\title{
REVIEW
}

\section{Pharmacogenomics of hepatitis C infections: personalizing therapy}

\author{
David R Booth*1 ${ }^{* 1}$ Golo Ahlenstiel ${ }^{2}$ and Jacob George ${ }^{2}$
}

\begin{abstract}
It is a widely held view that drug response genes have not proved as useful in clinical practice as anticipated at the start of the genomic era. An exception is in the treatment for chronic hepatitis $\mathrm{C}$ virus (HCV) genotype 1 infection with pegylated interferon a and ribavirin. In 2009, four independent genomewide analyses identified IL28B polymorphisms that predict drug response in chronic hepatitis $\mathrm{C}(\mathrm{CHC})$. This discovery had immediate clinical impact. First, the IL28B genotype could be used to personalize therapy. In the 2 years since discovery, most of the more than 100,000 CHC patients commencing therapy for CHC in the West will have considered IL28B genotype testing. Second, the discovery has supported clinical trials for the use of the protein encoded by the gene known as interferon lambda. Third, it is expected that new insights into HCV pathogenesis will follow from studies of how IL28B affects HCV viral clearance and, ultimately, this will lead to new therapeutic strategies for $\mathrm{CHC}$. This review discusses how IL28B genotyping is now used in personalizing therapy and, with the dramatically changing clinical landscape in $\mathrm{CHC}$, with the advent of direct-acting antivirals, the prospects ahead.
\end{abstract}

\section{IL28B and hepatitis C}

The recent rapid increase in knowledge of genetic variability and the decrease in the cost of genotyping were expected to lead to an explosion in the number of new diagnostic tests to predict drug response [1]. This has not happened, largely because drug response phenotypes, like many other phenotypes, are probably the net effects of numerous common genetic variants of small effect, and uncommon interacting variants of unknown

*Corresponding author: david.booth@sydney.edu.au

IInstitute for Immunology and Allergy Research, Westmead Millennium Institute,

University of Sydney, Australia

Full list of author information is available at the end of the article effect size. A striking exception is the prediction of response to pegylated interferon $\alpha$ and ribavirin (PegIFN/R) for the treatment for chronic hepatitis $\mathrm{C}(\mathrm{CHC})$. Four independent genome-wide analysis studies published at the end of 2009 and in early 2010 identified variants of the same single gene as predicting drug response [2-5]. This gene, IL28B, encodes a recently discovered interferon: interferon $\lambda 3$. The discovery was particularly exciting because the closely related interferon $\lambda 1$ had just been shown to have promise as an alternative to interferon $\alpha$ in phase 1 clinical trials for $\mathrm{CHC}$ [6].

CHC affects more than 180 million people or about 3\% of the world's population [7]. The majority of these are in Asia, the Middle East, Brazil and Indonesia; but there are also more than 10 million in the USA, Europe and Australia (Figure 1). Of those exposed to the virus, about a quarter spontaneously clear infection [8], while the majority develop chronic disease $[9,10]$. Disease progression in $\mathrm{CHC}$ is typically insidious, but a proportion will develop end-stage liver disease resulting in morbidity and mortality from liver failure and hepatocellular cancer.

The genome-wide analysis studies were performed in different geographic locales (Australia, Japan, Europe, USA) and in different ethnic populations (European, Japanese, African Americans, Hispanics), but all identified only the SNPs around $I L 28 B$ as associated with drug response, providing independent replication, and confirming that the data are robust and valid. In slightly over 2 years since these reports, several hundred studies have been published on $I L 28 B$ and hepatitis C, underlying the impact of this discovery on investigations of hepatitis $C$ virus $(\mathrm{HCV})$ pathobiology.

The importance of $I L 28 B$ for hepatitis C infection and the practice of hepatology is fourfold. First and foremost, it marks host genetic variation as an important player in the outcome of infection, bringing to the fore the era of personalized medicine. From a clinical perspective, genotyping for polymorphisms near the IL28B gene have impacted on decision making with regard to who to treat and when to treat with PegIFN/R, but also for the new direct-acting antiviral (DAA)-based therapies and interferon-free regimens $[11,12]$. From the perspective of pathogenesis, the discovery has led to important new 


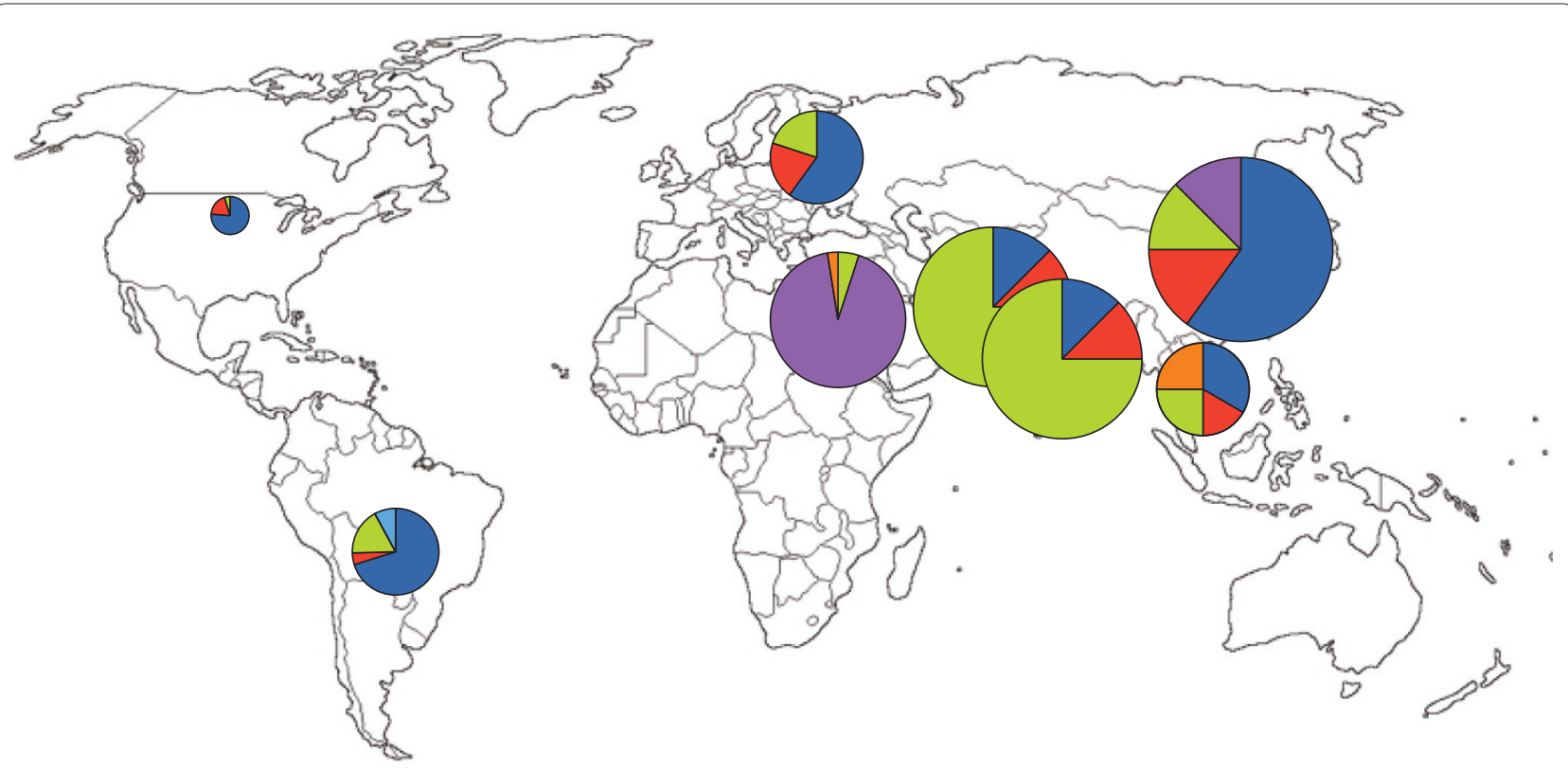

Figure 1. Global prevalence and genotypes of hepatitis C. Prevalence data are derived from Shepard et al. (2005) [28] and Te et al. (2010) [27]. Genotype data are from Shepard et al. (2005) [28] and Te et al. (2010) [27]. The pie chart diameter is Ln (number infected with hepatitis C virus) in the most populous areas of the world. The location of pie charts is approximate, based on the limited studies (reviewed in [27,28]). Colors in the pie charts represent HCV genotypes: 1, blue; 2, red; 3, green; 4, purple; 5, light blue; 6, orange. Approximately 30 million sub-Saharan Africans have chronic hepatitis $\mathrm{C}$, with widely variant genotypes around the continent.

knowledge, with type III interferons recognized as the predominant interferon produced by HCV infection in humans and chimpanzees and that best correlates with induction of interferon-sensitive genes (ISGs) [13]. Finally, from a therapeutic perspective, the type III interferons might have a specific role in therapy, with the downstream signaling pathways and their modulation an attractive target for drug development.

Given that humans and HCV, and their ancestors, have co-evolved over millennia in different ethnogeographic contexts and have been subject to divergent selection pressures, it is to be expected that both organisms will develop genetic variations that improve survival. For humans, the fact that some individuals but not others spontaneously clear virus suggests that innate and adaptive immune response variations determine the outcome of infection. Viral genomic variation allows for evasion of the host immune response and in this context, suboptimal host responses predispose to the development of chronic infection. Interferons play a major role in the response to viral infections, including to $\mathrm{HCV}$ specifically, in both humans and chimpanzees [14-17]. Type I interferons, IFN $\alpha$ and IFN $\beta$, are produced in response to signaling through viral recognition receptors, and utilize the same receptor. The type II interferon (IFNY) is proinflammatory, regulating the direct $\mathrm{T}$-cell and other responses. The three type III interferons (IFN $\lambda 1$ to 3 ) are transcribed from a gene cluster on chromosome 19, are highly homologous, and upregulate the same set of genes as type I interferons, but through a different receptor [18]. It follows that host genetic variation, particularly in innate response pathways, will likely contribute to predicting outcome to treatment with interferon-based regimes. Likewise, viral genomic variation may explain treatment failure in some individuals.

This review will focus on the pharmacogenetic applications of IL28B genotyping, the only genetic variant currently used diagnostically to predict drug response. The effectiveness of this genotyping for prediction of therapeutic response and clinical management for dual therapy (PegIFN/R) and triple therapy (PEGIFN/R and DAA) for the different viral subtypes will be discussed. Also discussed are the other genes that have been implicated in prediction for HCV treatment, and other diseases and therapies that might be affected by the IL28B genotype.

\section{Prediction of response to PegIFN/R therapy} The need for prediction of drug response

$\mathrm{HCV}$ is mostly spread by blood-blood transmission: typically through transfusion before screening for $\mathrm{HCV}$ was mandatory, shared needles in the context of injecting drug use, and use of non-sterile medical devices. If the virus is not cleared spontaneously, it establishes chronic infection of the liver, leading to fibrosis and loss of liver function, some 15 or more years after onset. At this 
point, the patient with symptoms will present to a clinician. To avoid the risk of liver failure or hepatocellular carcinoma, the patient needs to clear virus. The standard of care treatment in most of the world is PegIFN/R, which is very expensive (about US $\$ 20,000$ per year). Treatment of the most common viral genotype requires 48 weeks of injection with weekly pegylated interferon $\alpha$, and daily ribavirin tablets. Most patients report flu-like symptoms and neuropsychiatric adverse reactions, but improved therapies are now becoming available. As disease progression is relatively slow, patients are very keen to know if they are likely to benefit from currently available therapy, or if they should wait for the new, probably more expensive, therapies.

For PegIFN/R, IL28B genotyping can predict the chance of achieving a sustained viral response (SVR) or, as explained below, the likelihood of failing to achieve an SVR. The rs12979860 SNP CC genotype predicts response, and the CT and TT genotypes predict non-response [2]. The rs8099917 SNP TT genotype predicts response, and the GT and GG genotypes predict non-response [3,4]. In east and north Asians, the rs12979860 and rs8099917 SNPs can be used interchangeably in prediction because of the high degree of linkage disequilibrium, meaning that an rs129798690 C is virtually always inherited with an rs8099917 T. In patients of European descent, differing results are obtained with regard to the positive predictive value (PPV) for the SNPs. Based on 941 previously untreated patients of European descent with genotype 1 $\mathrm{CHC}$ and known treatment response examined for rs12979860 and rs8099917, the rs12979860 CC had a higher PPV for treatment success (64\% versus 55\% for rs8099917). In contrast, when the PPV for treatment failure was considered, then rs 8099917 GG had a higher PPV (73\% versus 69\% for rs12979860) [13]. These data indicate differential effects of the SNPs, most likely at the haplotype level (discussed below). In Europeans, an rs12979860 T can be on an allele with rs8099917 G (haplotype 2; Table 1), with the highest prediction of non-response. Or, it can be on an allele with rs8099917 T (haplotypes 3, 5 and 6), which does not increase the risk of treatment failure. Consequently, of the $50 \%$ of rs12979860 CTs, those whose T occurs with rs8099917 G have a poor chance of response (30\%), while those with rs8099917 $\mathrm{T}$ have a better than average chance of response (Figure 2) [19,20].

The responses in Figure 2 are from cross-sectional cohorts, reflective of the clinical situation. It is important to note that PPVs for success are higher in clinical trial cohorts, where adherence to regimes is monitored. In the study by Ge et al. [2], 82\% of people of European descent cleared virus if rs12979860 CC genotype, 42\% if heterozygotes, and $33 \%$ if $\mathrm{TT}$ genotype. In people of African descent, rs8099917 is not in linkage disequilibrium with rs12979860 and does not predict response. The SNP rs12979860 does predict response, so that $53 \%$ of those with CC clear the virus, $19 \%$ of heterozygotes clear the virus, and $17 \%$ of those with TT clear the virus. For the same genotype, clearance in African Americans is much lower, and the basis for this has yet to be explained. One possibility is genetic variation in another gene, with human leukocyte antigen $\mathrm{C}(H L A-C)$ genotype being one candidate [21].

\section{The IL28B haplotypes}

From the genome-wide analysis studies there were several polymorphisms mapping to the $I L 28 B$ haplotype block associated with treatment-induced genotype 1 HCV clearance. rs12979860 is located $3 \mathrm{~kb}$ upstream of the $I L 28 B$ gene, while rs8099917 is located $8.9 \mathrm{~kb}$ from the start of transcription of $I L 28 B$ and $16 \mathrm{~kb}$ from the start of transcription of IL28A [2-4].

Haplotypes are groups of SNPs that are inherited together, so that the presence of one variant tags the presence of others; for example, a 'C' at rs12979860 indicates that the SNP at rs12980275 is an 'A' (Table 1). These two SNPs are currently used for IL28B genotyping tests. They were identified on genotyping chips loaded with haplotype-tagging SNPs, and as such any SNPs, including many not on the chips, that are also only on the haplotypes they tag could be as good for predicting response. The haplotype with the highest association with response failure is haplotype 2, tagged by rs 8099917 'G'. The other haplotypes do not appear to have equal effects on response. The ' $\mathrm{T}$ ' that predicts response failure for rs12979860 is on haplotype 2, but also on haplotypes 3 and 6, which affect drug response less.

The rs12979860 C allelic frequency varies significantly across populations, about $70 \%$ in northern Europeans, more than $90 \%$ in north and east Asians, and about 30\% in African populations where it is the minor allele (Table 2). This difference in allelic frequency for the most part underlies the ethnic-specific differences in response rates to PegIFN/R, accounting for the better response of Asians, and about half the difference in SVR rates between African Americans and Americans of European ancestry [2].

\section{Better SNPS for prediction from the haplotypes?}

There may be better SNPs in the IL28B region, tagging a less common haplotype. An unbiased approach to discover new and better SNPs near the $I L 28 B$ gene for response prediction, not limited by the genome-wide analysis study SNP design, is through next-generation sequencing technologies. Smith et al. [20] approached this using massively parallel sequencing of pooled DNA from 100 responders and 99 non-responders, and validated this in a cohort of 905 patients. Long-range 


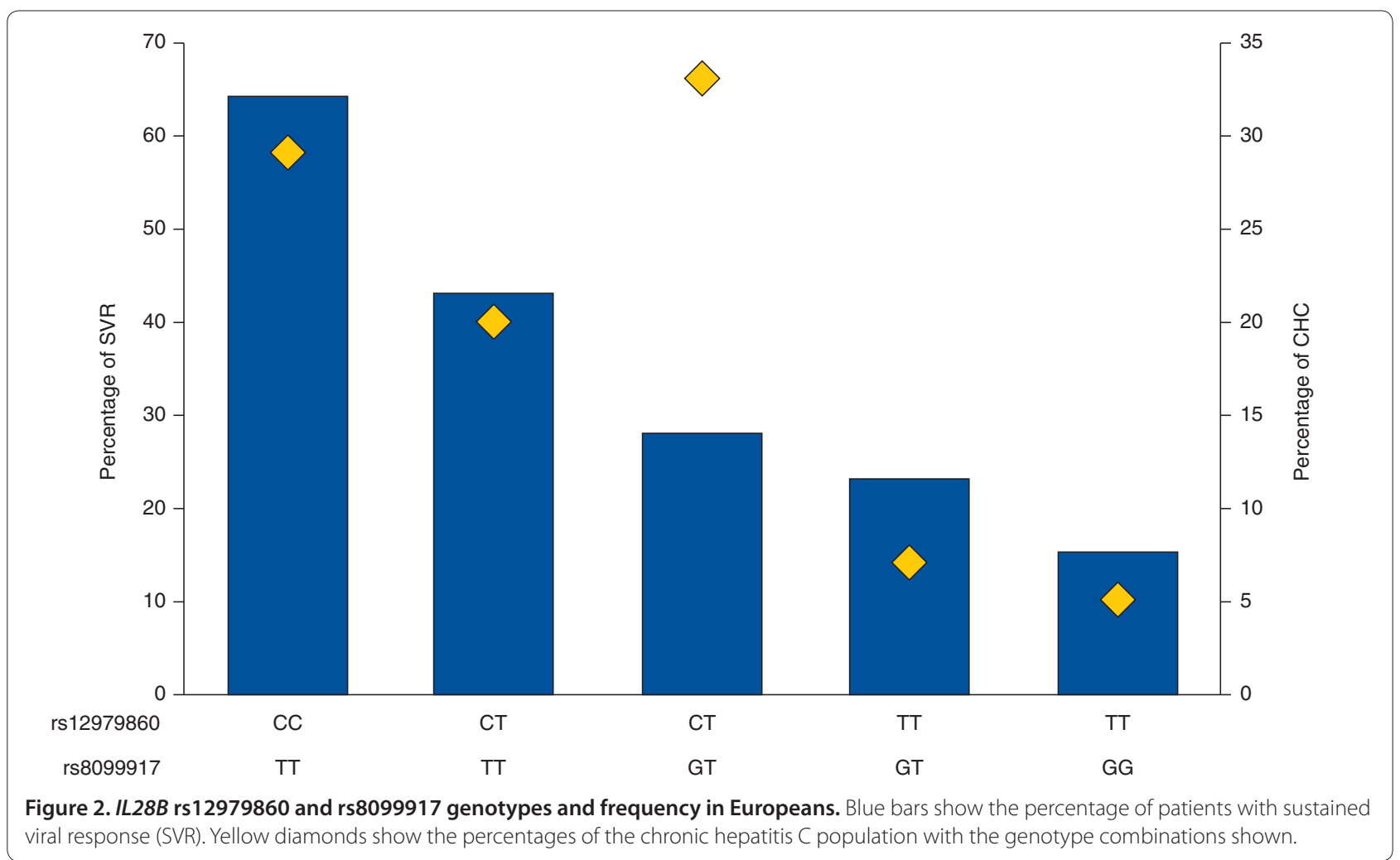

PCR was used to amplify a continuous $100 \mathrm{kbp}$ region of DNA containing the IL28A, IL28B and IL29 genes. Only SNPs in the $I L 28 B$ linkage disequilibrium block predicted drug response. Two SNPs, rs4803221 (homozygote minor allele PPV of 77\%) and rs7248668 (PPV 78\%), predicted failure to respond better than the rs8099917 (PPV 73\%) and rs12979860 (PPV 68\%) SNPs. The best SNPs tagged a single common haplotype, haplotype 2 , and genotypes predicted lack of response better than alleles.

Final decisions on the best $\mathrm{SNP}(\mathrm{s})$ may follow from identification of the functional haplotype or SNP, although haplotype tagging SNPs will likely be as effective for prediction as any causal SNP they are in complete linkage disequilibrium with. At this stage, haplotype 2 appears to be the causal haplotype. The African American non-response haplotype, currently best tagged by rs12979860 T, with less significant $P$ values as SNPs upstream and downstream are sampled, likely contains the functional $\operatorname{SNP}(\mathrm{s})[2,22]$. The SNP found to best predict response in the study by Smith et al. [20] was rs4803221, which is in the CpG region of the proximal promoter with rs12979860. It will be interesting to establish if the subsection of Africans with rs12979860 T and rs4803221 $\mathrm{G}$ have the lowest response. Other further refinements may follow from discovering rarer SNPs of bigger effects that may have been tagged by the haplotype SNPs. It is also possible that there are non-SNP genetic variants in this region causing the functional effect(s).
The underlying mechanism for the effect of host and viral genomes in predicting treatment response to PegIFN/R therapy is still unknown. Two early studies identified lower expression of the non-responder allele in whole blood from healthy controls $[3,4]$. Subsequent attempts to identify differential regulation of $I L 28 B$ by the alleles in blood, immune cells or hepatocytes have not been conclusive, although there is a strong correlation of the $I L 28 B$ non-responder allele with high expression of interferon-stimulated genes in infected hepatocytes but not uninfected hepatocytes, and evidence for lower expression of ISGs in immune cells of biopsies of infected liver tissue [23-25]. African American haplotypes are shorter and so ideal for narrowing down the potential functional SNPs on the functional haplotypes. This indicates the causal variant lies 5' of rs12979860 and 3' of rs12980275, encompassing the proximal promoter and coding region of the gene. Exonic changes on the nonresponder haplotype do not affect function in transformed cells $[23,26]$. The TA repeat polymorphism on the non-responder allele affects expression in the proximal promoter region of transformed cells [26]. Responder $I L 28 B$ alleles and wild-type core 70 mutations are associated with improved early viral kinetics. However, the mechanism for these effects is uncertain, possibly through effects on hepatic type III interferon and ISG induction. Indeed, raised ISG induction in hepatic biopsies of $\mathrm{CHC}$ patients is tightly correlated with the 
Table 1. Common SNPs across the IL28B gene region and their haplotypes

\begin{tabular}{|c|c|c|c|c|c|c|c|}
\hline \multirow[b]{2}{*}{ Location } & \multirow[b]{2}{*}{ SNP } & \multicolumn{6}{|c|}{ Haplotype } \\
\hline & & $1^{\mathrm{a}}$ & $2^{\mathrm{b}}$ & 3 & $4^{a}$ & 5 & 6 \\
\hline $5^{\prime}$ & rs7248668 & G & A & G & G & G & G \\
\hline $5^{\prime}$ & rs8099917c & $\mathrm{T}$ & G & $\mathrm{T}$ & $\mathrm{T}$ & $\mathrm{T}$ & $\mathrm{T}$ \\
\hline $5^{\prime}$ & rs8109886 & C & A & A & A & A & A \\
\hline $5^{\prime}, \mathrm{CpG}$ & rs4803221 & C & G & C & C & $C$ & G \\
\hline $5^{\prime}, \mathrm{CpG}$ & rs12979860 & C & $\mathrm{T}$ & $\mathrm{T}$ & C & $\mathrm{T}$ & $\mathrm{T}$ \\
\hline Exon 2 & rs8103142 & $\mathrm{T}$ & $C$ & C & $\mathrm{T}$ & C & C \\
\hline Intron 2 & rs11881222 & A & G & G & A & A & G \\
\hline $3^{\prime}$ & rs688187 & G & A & A & G & A & A \\
\hline $3^{\prime}$ & rs8105790 & $\mathrm{T}$ & C & C & $\mathrm{T}$ & $\mathrm{T}$ & C \\
\hline $3^{\prime}$ & rs12982533 & $\mathrm{T}$ & C & C & $\mathrm{T}$ & $\mathrm{T}$ & C \\
\hline $3^{\prime}$ & rs12980275 & A & G & G & A & A & G \\
\hline OR $(95 \% \mathrm{Cl})$ & & $\begin{array}{c}0.70 \\
(0.57-0.85)\end{array}$ & $\begin{array}{c}2.20 \\
(1.72-2.80)\end{array}$ & $\begin{array}{c}1.04 \\
(0.75-1.43)\end{array}$ & $\begin{array}{c}0.60 \\
(0.43-0.83)\end{array}$ & $\begin{array}{c}0.79 \\
(0.39-1.60)\end{array}$ & $\begin{array}{c}1.49 \\
(0.62-3.56)\end{array}$ \\
\hline \%CEU (CHC) & & 43.2 & 23.8 & 10.3 & 9.8 & 1.9 & 1.4 \\
\hline
\end{tabular}

aHighest sustained viral response. ${ }^{b} \mathrm{C}$ ausal haplotype; lowest sustained viral response. cSNPs currently used for genotyping to decide $\mathrm{CHC}$ treatment. Odds ratio (OR) and percentage of haplotypes in chronic hepatitis $\mathrm{C}(\mathrm{CHC})$ in patients of European descent $(\mathrm{CEU})$ are from Smith et al. [20]. $\mathrm{Cl}$, confidence interval.

non-responder haplotypes, and provides slightly better prediction of SVR $[24,25]$.

\section{Prediction of clearance for different HCV genotypes}

$\mathrm{HCV}$ viruses are classified into six genotypes, with genotype 1 being the most widespread (China, Europe, America, Australia) and common $[27,28]$, the least susceptible to PegIFN/R treatment, and for which prediction from IL28B genotype is most useful.

The role of viral genomes in predicting the response to treatment is contentious. Viral genotype and load are important and established predictors of response. Most studies of viral mutations have been from Japan and in persons infected with $\mathrm{HCV}$ genotype $1 \mathrm{~b}$, where amino acid substitutions at positions 70 and 91 of the HCV core protein and substitutions in the interferon sensitivity determining region (ISDR) of the NS5A protein have been shown to be associated with treatment outcome. The role of $I L 28 B$ polymorphisms and the above substitutions were recently reported from 817 Japanese patients with genotype 1b CHC [29]. In that report, IL28B rs12979860 CC, core amino acid 70 substitution (nonarginine; odds ratio (OR) $0.53, P=0.016$ ), age and viral load were predictive of SVR, while IL28B CC genotype, core amino acid 70 substitutions $(P=0.0013)$, ISDR substitutions $(P=0.0019)$, viral load GGT, ALT and platelet count were predictive of a rapid virological response (RVR).

The role of $I L 28 B$ SNPs in predicting the outcome of PegIFN/R treatment of infection with genotypes 2 to 6 is controversial. These other genotypes are more responsive to therapy, with around $80 \%$ of those infected with genotype 2 clearing virus on treatment [30]. IL28B genotype is correlated with success, but only improves prediction by around 5\%. Mangia et al. [31], using a cohort of 268 Caucasian patients with HCV genotype 2 or 3 infection treated with combination therapy, found that IL28B SNPs were associated with SVR principally in those that did not achieve an RVR. In subsequent studies, IL28B SNPs have been associated with RVR and variably with SVR. Genotype 3, the most common type in India and Pakistan, is thought to be similarly susceptible to PegIFN/R to genotype 2, but clearance success in these different clinical settings has yet to be established. Genotype 4 is thought to be cleared with intermediate efficacy between genotypes 1 and $2 / 3$. It is the most common type in the many millions infected in the Middle East, with near 20\% prevalence in the population of Egypt. In a single small study of genotype 4 infected patients, $I L 28 B$ genotype was shown to influence RVR, SVR and SVR in non-RVR patients [32]. Genotype 6 is the most common form in the many millions infected in Southeast Asia, and genotype 5 the most common in southern Africa [27,28]. All genotypes are found in Africa, where at least 30 million are thought to be infected, but where genotypes and treatment responses are not well characterized.

\section{Post-treatment prediction of response}

For HCV genotype 1, within $24 \mathrm{~h}$ of first injection, there is a rapid, $I L 28 B$ genotype-dependent, reduction of $\mathrm{HCV}$ viral load [33]. By week 4, undetectable HCV (RVR) 
Table 2. Common SNPs across the IL28B gene region have very different minor allele frequencies in the major ethnic groups

\begin{tabular}{|c|c|c|c|c|c|}
\hline Location & SNP & OR & $\%$ CEU & $\% \mathrm{CHI}$ & \%YRI \\
\hline $5^{\prime}$ & rs7248668 & $2.24^{b}$ & 17 & 7 & 6 \\
\hline $5^{\prime}$ & rs8099917c & $1.91^{\mathrm{b}}$ & 17 & 8 & 6 \\
\hline $5^{\prime}$ & rs8109886 & $0.67^{a}$ & 43 & 7 & 80 \\
\hline $5, C p G$ & rs4803221 & $2.24^{b}$ & 17 & 7 & 18 \\
\hline $5, C p G$ & rs12979860 & $1.99^{\mathrm{b}}$ & 32 & 8 & 60 \\
\hline Exon 2 & rs8103142 & $1.50^{\mathrm{b}}$ & 27 & 4 & 56 \\
\hline Intron 2 & rs11881222 & $2.02^{\mathrm{b}}$ & 30 & 7 & 31 \\
\hline $3^{\prime}$ & rs688187 & $1.94^{\mathrm{b}}$ & 32 & 7 & 59 \\
\hline $3^{\prime}$ & rs8105790 & $1.63^{b}$ & 17 & 7 & 19 \\
\hline $3^{\prime}$ & rs12982533 & $2.01^{b}$ & 31 & 8 & 39 \\
\hline $3^{\prime}$ & rs 12980275 & $1.79^{b}$ & 31 & 8 & 51 \\
\hline
\end{tabular}

${ }^{\mathrm{a}}$ Minor allele predicts treatment success. ${ }^{\mathrm{b}}$ Minor allele predicts treatment failure. 'SNPs currently used in genotyping to decide treatment for CHC. \%, Percentage of SNPs in major ethnic groups. CEU, European; CHI, Han Chinese; YRI, Yorubi Africans. SNP frequencies are from the 1000 Genome Project pilot genotyping data.

predicts clearance better than IL28B genotype, and response-guided therapy, where the time on treatment is determined from the decline in viral load, is based on viral load changes. Even using triple therapy, where PegIFN/R is augmented with telaprevir, for those with the non-responder genotype who do not achieve an RVR, the chances of clearing virus by the end of therapy is $0 \%$, and $59 \%$ for those who do achieve RVR; whereas for those homozygous for the responder genotype, 16\% will not clear virus if they have not achieved RVR, whereas $84 \%$ will clear if they have achieved RVR [34].

Combining RVR, HCV genotype and IL28B genotype may prove useful in guiding therapy where cost is limiting or dependent on time on therapy, particularly in the new era of DAAs (see below).

\section{Other host genes and the prediction of viral clearance}

It is striking that in all the genome-wide analysis studies to date, and including genes from the $\mathrm{MHC}$ region, only $I L 28 B$ reaches genome-wide statistical significance. Certain genetic variants are not amenable to SNP chip analysis. These include the MHC region variants and deletion variants such as CCR5 delta 32. In a recent report, Suppiah et al. [21] studied the combined effect of IL28B SNPs with HLA-C, and their ligands, the killer immunoglobulin-like receptors in predicting treatmentinduced clearance $(n=417)$ or failure $(n=493)$ in Caucasian patients with genotype $1 \mathrm{CHC}$. The rs8099917 non-responder $G$ allele was associated with failure to clear on treatment (OR 2.19, $P=1.27 \times 10^{-6}, 1.67$ to 2.88 ) and absence of spontaneous clearance (OR 3.83, $P=1.71 \times 10^{-14}, 2.67$ to 5.48$)$, as was rs12979860, with slightly lower ORs. The HLA-C C2C2 genotype was also over-represented in patients who failed treatment $(P=0.024)$. The prediction of non-response improved from $66 \%$ using $I L 28 B$ to $80 \%$ using both $I L 28 B$ and HLA-C (OR 3.78, $P=8.83 \times 10^{-6}, 2.03$ to 7.04). Using logistic regression, the combination rs8099917, $\mathrm{G}^{*} / \mathrm{C} 2 \mathrm{C} 2$ was shown to be partially due to genetic interaction and not just an additive effect, consistent with the known role of HLC-C in the pathogenesis of HCV infection. This combination is present in about $20 \%$ of the Caucasian population, and captures a higher percentage of nonresponders than using homozygote non-responders alone (Table 3). While the data need replication, the combination of IL28B and HLA-C SNPs appears to improve diagnostic accuracy and clinical utility. Natterman et al. [35] found that prediction of spontaneous clearance in a German cohort was improved using both CCR5delta32 and $I L 28 B$ rs12979860 SNP. It remains to be seen if these two genes interact in predicting SVR.

\section{Impact of other clinical parameters with IL28B genotype}

Clinical and genomic data can be combined for predicting response to combination therapy with PegIFN/RBV in genotype $1 \mathrm{CHC}$ [36]. More recently, serum IP10 [37], 25 hydroxyvitamin D3 and SNPs in the vitamin D binding protein [38], and hepatic ISG expression [23-25] have been shown to be additional factors predicting the outcome of therapy. However, while these markers in combination improve diagnostic utility, large-scale prospective trials are unlikely to eventuate given the rapid development of DAA-based regimens.

\section{Prediction of clearance for HIV-HCV co-infection}

Because HCV and HIV are both blood-borne viruses, where risks of infection are increased by similar practices, co-infection is common. In these cases, two studies have indicated a higher risk of mortality for the rs12979860 $\mathrm{CC}$ genotype on antiviral treatment for HIV. In one study, 
Table 3. Combining HLA-C and IL28B genotypes to improve prediction

\begin{tabular}{llccc}
\hline Genotype & & \% of CHC & \% of NSVR & \% with NSVR \\
\hline HLA-C & IL28B & & & \\
& rs8099917 & & & \\
Any & GG(1) & 6 & 10 & 73 \\
Any & $G^{*}$ & 48 & 57 & 64 \\
C2C2 & Any & 17 & 32 & 20 \\
C2C2 & $G^{*}(2)$ & 8 & 12 & $80^{\mathrm{b}}$ \\
& $(1)+(2)$ & 12 & $18^{\mathrm{a}}$ & $77^{\mathrm{a}}$ \\
& rs12979860 & & & \\
Any & TT(3) & 15 & 19 & 68 \\
Any & $T^{*}$ & 68 & 79 & 63 \\
C2C2 & Any & 17 & 21 & 64 \\
C2C2 & $T^{*}(4)$ & 13 & 18 & 73 \\
& $(3)+(4)$ & 26 & 33 & 70 \\
\hline
\end{tabular}

CHC, chronic hepatitis C; NSVR, non-sustained viral response. aslightly lower prediction percentage, but identifies a higher percentage of NSVR. ${ }^{b} B e s t$ prediction. Data from Suppiah et al. [21].

the rs12979860 CC genotype was associated with 54\% higher mortality risk compared with TT genotype in HIV-HCV co-infected individuals [39]. In another, the increased risk was $80 \%$ [40]. The authors in the latter study speculated that this was due to higher baseline plasma HIV viremia and possibly altered immune reconstitution associated with interferon $\lambda$ expression. Vispo et al. [41] found evidence that $I L 28 B$ genotype predicted clearance of HCV genotype $1 \mathrm{a}$, but not $1 \mathrm{~b}$, in $\mathrm{HIV} / \mathrm{HCV}$ co-infection. Dayyeh et al. [42] have suggested that therapy should be delayed in those with non-responder genotypes and $\mathrm{HCV}$ genotype 1 infection, depending on the baseline viral load.

\section{Association of host genetic variants with other treatment adverse reactions}

The major adverse reactions to treatment with PegIFN/R are IFN-induced neutropenia and leucopenia, and ribavirin-induced hemolysis. Two genome-wide analyses, one in Japanese [43] and one in Europeans [44], found that SNPs at the inosine triphosphatase (ITPA) locus predicted ribavirin-related hemolysis. No genetic variants were identified associated with neutropenia or leucopenia.

\section{Association of host genetic variants with other viral diseases and drug responses}

To date, no association of $I L 28 B$ genotype with clearance or response to treatment of other flaviviruses (a group that includes arboviruses such as dengue and West Nile virus) has been reported. This may await interrogation of appropriate cohorts. It may also represent different tropisms of these viruses, to tissues not so dependent on expression of the IL28 receptor. Other RNA viruses, such as influenza, do infect tissues that express the receptor, and so may be affected by $I L 28 B$ genotype - this has yet to be established. Although IL28B was not associated with clearance of HIV [45] or hepatitis B $[45,46]$, the IL28B genotype can affect clearance of hepatitis $\mathrm{B}$ on interferon therapy in European and Chinese cohorts [47,48].

Type 1 interferons are used to treat autoimmune diseases such as multiple sclerosis, and antibodies to interferon $\alpha$ are used to treat systemic lupus erythamotosis, as well as many other inflammatory and autoimmune conditions [18]. It has also yet to be established if the IL28B genotype affects response to interferons in these diseases.

\section{Prediction of response with DAAs}

Therapy for $\mathrm{HCV}$ infection is currently undergoing a radical transformation with the advent of oral medications: the DAAs. The first two to receive US Food and Drug Administration (FDA) approval are the NS3 protease inhibitors boceprevir and telaprevir. These have cure rates substantially higher (about 70 to $80 \%$ ) than dual therapy with PegIFN/R ( $<50 \%)$, and may allow reduction in treatment duration [49,50] (Table 4). To minimize the risk of viral resistance, both are used with a PegIFN/R pre-treatment. For both, IL28B genotype predicts SVR. For telaprevir, cure rates (SVR) vary from $90 \%$ for rs12979860 CCs, to $73 \%$ for TTs. Clearance at 8 weeks for boceprevir/PegIFN/R was achieved for $89 \%$ of CCs and $52 \%$ of CT/TTs; and at 4 and 12 weeks (no $\mathrm{HCV}$ detected at both time points) for $72 \%$ of CCs and $52 \%$ of CT/TTs. Many more DAAs are in late-stage clinical trials and producing very promising results [51]. They have been so rapidly taken up, especially in the USA, that triple therapy is now considered the new standard of care treatment for genotype $1 \mathrm{HCV}$ there [12]. Dual therapy remains the standard of care treatment for other viral genotypes.

However, enthusiasm for these regimens is tempered by the substantially lower cure rates (about 30\%) in previous PegIFN/R null responders. In all those failing single DAA-based therapy, future treatment with multiple DAA-based combinations with or without PegIFN/R may be compromised by the development of drug resistance. Further, HCV eradication using single DAA-based strategies, particularly in previous treatment failures, appears to be $I L 28 B$ genotype dependent. In this context, predicting non-response rather than success is paramount since the former should perhaps have therapy deferred until multiple DAA-based combinations become available. The present results therefore provide a strong rationale for the use of IL28B SNPs such as rs4803221 in combination with the HLA-C genotype, such that those with nonresponse genotypes are considered for future regimens rather than single DAA-based therapy. 
Table 4. Effect of rs 12979860 genotype on percentage sustained viral response for boceprevir and telaprevir treatment regimes

\begin{tabular}{lcccc}
\hline & \multicolumn{4}{c}{ Genotype (\%SVR) } \\
\cline { 2 - 5 } Treatment & CC & CT & TT \\
\hline SPRINT-2 $(n=653)$ & 78 & 28 & 27 & \\
PegIFN/R & 82 & 65 & 55 & \\
BOC/RGT & 80 & 71 & 59 & \\
BOC/PR48 & 89 & 52 & & \\
No HCV at 8 weeks & & & & \\
ADVANCE $(n=454)$ & 64 & 25 & 23 \\
$\quad$ PegIFN/R & 84 & 57 & 59 & \\
T8 24/48 & 90 & 71 & 73 \\
T12 24/48 & 72 & 52 & \\
No HCV at 4 and 12 weeks & 72 & & \\
\hline
\end{tabular}

$\%$ SVR, percentage sustained viral response. Data from SPRINT-2 (boceprevir, BOC) [49] and ADVANCE (telaprevir, T) clinical trials [50]. SPRINT-2 regime: PegIFN/R for 48 weeks. BOC/RGT: PegIFN/R for 4 weeks, then 24 weeks; BOC and PegIFN/R if HCV undetectable, 44 weeks if not. BOC/PR48: PegIFN/R for 4 weeks, then 44 weeks BOC and PegIFN/R. No hepatitis $C$ virus (HCV) based on detection at 8 weeks. ADVANCE regime: PegIFN/R for 48 weeks. T8 24/48: telaprevir for 8 weeks, PegIFN/R for 24 or 48 weeks, dependent on HCV at 4 and 12 weeks. T12 24/48: telaprevir for 12 weeks, PegIFN/R for 24/48 weeks. No HCV based on detection at 4 and 12 weeks of treatment.

\section{Conclusion}

Internationally, in the next few years, hundreds of thousands to millions of people with $\mathrm{HCV}$ are likely to consider therapy to clear virus, and consideration of $I L 28 B$ genotype may aid in pre-treatment choice of therapy. As discussed above, such testing can predict the difference between a $15 \%$ chance of clearance (for example, for those with $\mathrm{HCV}$ genotype 1a and HIV coinfection, or those with rs8099917 GG and HLA-C C2C2 genotypes) to $100 \%$ chance of clearance (rs12979860 CC on DAA), depending on the treatment chosen, $\mathrm{HCV}$ genotype and HIV co-infection status. This decision will also be greatly affected by the cost of therapeutic options, with vastly different parameters in western countries, Asia, the Middle East and Africa. To the armory of information already obtained will come a need to gather more for the new therapeutic options and for the vastly different clinical settings in the different parts of the world. Specifically, new genetic variants (SNPs, insertions, deletions, gene copy number variants, even RNA isoforms) may identify the few who fail to respond to the triple therapies. Next-generation sequencing studies to identify viral variants that resist particular therapies will be needed. Clinical management may need to be guided by monitoring of the emergence of such viral variants and the rebound of viral load.

\section{Abbreviations}

$\mathrm{CHC}$, chronic hepatitis $\mathrm{C}$; DAA, direct-acting antiviral; $\mathrm{HCV}$, hepatitis $\mathrm{C}$ virus; HLA-C, human leukocyte antigen C; ISDR, interferon sensitivity determining region; ISG, interferon sensitive gene; kb, kilobase; OR, odds ratio; PegIFN/R, pegylated interferon and ribavirin; PPV, positive predictive value; RVR, rapid viral response; SNP, single nucleotide polymorphism; SVR, sustained viral response.

\section{Competing interests}

DB and JG have patent applications for using IL28B and $H L A-C$ to predict drug response.

\section{Acknowledgements}

This work was funded by an Australian National Health and Medical Research Council Project Grant, a MS Senior Research Fellowship to DB, and the Robert W Storr Bequest to the Sydney Medical Foundation.

\section{Author details}

IInstitute for Immunology and Allergy Research, Westmead Millennium Institute, University of Sydney, Australia. ${ }^{2 S}$ Storr Liver Unit, Westmead Millennium Institute, University of Sydney, Australia.

Published: 26 December 2012

\section{References}

1. Manolio TA: Genome-wide association studies and assessment of the risk of disease. NEngl J Med 2010, 363:166-176.

2. Ge D, Fellay J, Thompson AJ, Simon JS, Shianna KV, Urban TJ, Heinzen EL, Qiu P, Bertelsen AH, Muir AJ, Sulkowski M, McHutchison JG, Goldstein DB: Genetic variation in IL28B predicts hepatitis $C$ treatment-induced viral clearance. Nature 2009, 461:399-401.

3. Suppiah V, Moldovan M, Ahlenstiel G, Berg T, Weltman M, Abate ML, Bassendine M, Spengler U, Dore GJ, Powell E, Riordan S, Sheridan D, Smedile A, Fragomeli V, Müller T, Bahlo M, Stewart GJ, Booth DR, George J: IL28B is associated with response to chronic hepatitis $C$ interferon-alpha and ribavirin therapy. Nat Genet 2009, 41:1100-1104.

4. Tanaka Y, Nishida N, Sugiyama M, Kurosaki M, Matsuura K, Sakamoto N, Nakagawa M, Korenaga M, Hino K, Hige S, Ito Y, Mita E, Tanaka E, Mochida S, Murawaki Y, Honda M, Sakai A, Hiasa Y, Nishiguchi S, Koike A, Sakaida I, Imamura M, Ito K, Yano K, Masaki N, Sugauchi F, Izumi N, Tokunaga K, Mizokami M: Genome-wide association of IL28B with response to pegylated interferon-alpha and ribavirin therapy for chronic hepatitis $C$. Nat Genet 2009, 41:1105-1109.

5. Rauch A, Kutalik Z, Descombes P, Cai T, Di Iulio J, Mueller T, Bochud M, Battegay M, Bernasconi E, Borovicka J, Colombo S, Cerny A, Dufour JF, Furrer H, Günthard HF, Heim M, Hirschel B, Malinverni R, Moradpour D, Müllhaupt B, Witteck A, Beckmann JS, Berg T, Bergmann S, Negro F, Telenti A, Bochud PY; Swiss Hepatitis C Cohort Study; Swiss HIV Cohort Study: Genetic variation in IL28B is associated with chronic hepatitis C and treatment failure: a genome-wide association study. Gastroenterology 2010, 138:1338-1345.

6. Muir AJ, Shiffman ML, Zaman A, Yoffe B, de la Torre A, Flamm S, Gordon SC, Marotta P, Vierling JM, Lopez-Talavera JC, Byrnes-Blake K, Fontana D, Freeman J, Gray T, Hausman D, Hunder NN, Lawitz E: Phase 1b study of pegylated interferon lambda 1 with or without ribavirin in patients with chronic genotype 1 hepatitis C virus infection. Hepatology 2010, 52:822-832.

7. World Health Organization (WHO): Hepatitis C. Fact Sheet No. 164. Revised July 2012 [http://www.who.int/mediacentre/factsheets/fs164/en/]

8. Micallef JM, Kaldor JM, Dore GJ: Spontaneous viral clearance following acute hepatitis $C$ infection: a systematic review of longitudinal studies. J Viral Hepat 2006, 13:34-41.

9. Hoofnagle, JH: Course and outcome of hepatitis C. Hepatology 2002, 36:S21-S29.

10. Thomas DL, Seeff LB: Natural history of hepatitis C. Clin Liver Dis 2005 , 9:383-398.

11. Chu TW, Kulkarni R, Gane ED, Roberts SK, Stedman C, Angus P, Ritchia B, Lu XY, Ipe D, Lopatin U, Germer S, Iglesias VA, Elston R, Smith PF, Shulman NS: Effect of IL28B genotype on early viral kinetics during interferon-free treatment of patients with chronic hepatitis C. Gastroenterology 2012, 142:790-795.

12. Ghany MG, Nelson DR, Strader DB, Thomas DL, Seeff LB; American Association for Study of Liver Diseases: An update on treatment of genotype 1 chronic hepatitis C virus infection: 2011 practice guideline by the American Association for the Study of Liver Diseases. Hepatology 2011, 54:1433-1444.

13. Thomas E, Gonzalez VD, Li Q, Modi AA, Chen W, Noureddin M, Rotman Y, Liang TJ: HCV infection induces a unique hepatic innate immune response 
associated with robust production of type III interferons. Gastroenterology 2012, 142:978-988.

14. Bigger CB, Guerra B, Brasky KM, Hubbard G, Beard MR, Luxon BA, Lemon SM Lanford RE: Intrahepatic gene expression during chronic hepatitis $C$ virus infection in chimpanzees. J Virol 2004, 78:13779-13792.

15. Sarasin-Filipowicz M, Oakeley EJ, Duong FH, Christen V, Terracciano L, Filipowicz W, Heim MH: Interferon signalling and treatment outcome in chronic hepatitis C. Proc Natl Acad Sci U S A 2008, 105:7034-7039.

16. Su Al, Pezacki JP, Wodicka L, Brideau AD, Supekova L, Thimme R, Wieland S, Bukh J, Purcell RH, Schultz PG, Chisari FV: Genomic analysis of the host response to hepatitis C virus infection. Proc Natl Acad Sci U S A 2002 99:15669-15674

17. Thomas DL, Thio CL, Martin MP, Oi Y, Ge D, O'Huigin C, Kidd J, Kidd K, Khakoo SI, Alexander G, Goedert JJ, Kirk GD, Donfield SM, Rosen HR, Tobler LH, Busch MP, MCHutchison JG, Goldstein DB, Carrington M: Genetic variation in IL28B and spontaneous clearance of hepatitis C virus. Nature 2009, 461:798-801.

18. Hertzog PJ: Overview. Type I interferons as primers, activators and inhibitors of innate and adaptive immune responses. Immunol Cell Biol 2012, 90:471-473.

19. Fischer J, Böhm S, Scholz M, Müller T, Witt H, George J, Sarrazin C, Susser S, Schott E, Suppiah V, Booth DR, Stewart GJ, van Bömmel F, Brodzinski A, Fülöp $B$, Migaud P, Berg T: Combined effects of different interleukin-28B gene variants on the outcome of dual combination therapy in chronic hepatitis C virus type 1 infection. Hepatology 2012, 55:1700-1710.

20. Smith KR, Suppiah V, O'Connor K, Berg T, Weltman M, Abate ML, Spengler U, Bassendine M, Matthews G, Irving WL, Powell E, Riordan S, Ahlenstiel G, Stewart GJ, Bahlo M, George J, Booth DR; the International Hepatitis C Genetics Consortium: Identification of improved IL28B SNPs and haplotypes for prediction of drug response in treatment of hepatitis $C$ using massively parallel sequencing in a cross-sectional European cohort. Genome Med 2011, 3:57.

21. Suppiah V, Gaudieri S, Armstrong N, O'Connor KS, Berg T, Weltman M, Abate ML. Spengler U, Bassendine M, Dore GJ, Irving WL, Powell E, Hellard M, Riordan S, Matthews G, Sheridan D, Nattermann J, Smedile A, Muller T, Hammond E, Dunn D, Negro F, Bochud PY, Mallal S, Ahlenstiel G, Stewart GJ, George J, Booth DR for the International Hepatitis C Genetics Consortium: IL28B, HLA-C and KIR variants additively and interactively predict response to therapy in chronic hepatitis C Virus infection. PLoS Med 2011, 8:e1001092.

22. Afdhal NH, McHutchison JG, Zeuzem S, Mangia A, Pawlotsky JM, Murray JS, Shianna KV, Tanaka Y, Thomas DL, Booth DR, Goldstein DB; Pharmacogenetics and Hepatitis C Meeting Participants: Hepatitis C pharmacogenetics: state of the art in 2010. Hepatology 2011, 53:336-345.

23. Urban TJ, Thompson AJ, Bradrick SS, Fellay J, Schuppan D, Cronin KD, Hong L, McKenzie A, Patel K, Shianna KV, McHutchison JG, Goldstein DB, Afdhal N: IL28B genotype is associated with differential expression of intrahepatic interferon-stimulated genes in patients with chronic hepatitis C. Hepatology 2010, 52:1888-1896.

24. Dill MT, Duong FH, Vogt JE, Bibert S, Bochud PY, Terracciano L, Papassotiropoulos A, Roth V, Heim MH: Interferon-induced gene expression is a stronger predictor of treatment response than IL28B genotype in patients with hepatitis C. Gastroenterology 2011, 140:1021-1031.

25. Honda M, Sakai A, Yamashita T, Nakamoto Y, Mizukoshi E, Sakai Y, Yamashita T, Nakamura M, Shirasaki T, Horimoto K, Tanaka Y, Tokunaga K, Mizokami M, Kaneko S: Hokuriku Liver Study Group: Hepatic ISG expression is associated with genetic variation in interleukin $28 \mathrm{~B}$ and the outcome of IFN therapy for chronic hepatitis C. Gastroenterology 2010, 139:499-509.

26. Sugiyama M, Tanaka Y, Wakita T, Nakanishi M, Mizokami M: Genetic variation of the IL-28B promoter affecting gene expression. PLoS One 2011, 6:e26620.

27. Te HS, Jensen DM: Epidemiology of hepatitis $B$ and $C$ viruses: a global overview. Clin Liver Dis 2010, 14:1-21.

28. Shepard CW, Finelli L, Alter MJ: Global epidemiology of hepatitis C virus infection. Lancet Infect Dis 2005, 5:558-567.

29. Hayes CN, Kobayashi M, Akuta N, Suzuki F, Kumada H, Abe H, Miki D, Imamura M, Ochi H, Kamatani N, Nakamura Y, Chayama K: HCV substitutions and IL28B polymorphisms on outcome of peg-interferon plus ribavirin combination therapy. Gut 2011, 60:261-267.

30. Schreiber J, Moreno C, Garcia BG, Louvet A, Trepo E, Henrion J, Thabut D, Mathurin P, Deltenre P: Meta-analysis: the impact of IL28B polymorphisms on rapid and sustained virological response in $\mathrm{HCV}-2$ and -3 patients. Aliment Pharmacol Ther 2012, 36:353-362.
31. Mangia A, Thompson AJ, Santoro R, Piazzolla V, Tillmann HL, Patel K, Shianna KV, Mottola L, Petruzzellis D, Bacca D, Carretta V, Minerva N, Goldstein DB, McHutchison JG: An IL28B polymorphism determines treatment response of hepatitis $C$ virus genotype 2 or 3 patients who do not achieve a rapid virologic response. Gastroenterology 2010, 139:821-827.

32. De Nicola S, Aghemo A, Rumi MG, Galmozzi E, Valenti L, Soffredini R, De Francesco R, Prati GM, D'Ambrosio R, Cheroni C, Donato MF, Colombo M: Interleukin $28 \mathrm{~B}$ polymorphism predicts pegylated interferon plus ribavirin treatment outcome in chronic hepatitis C genotype 4. Hepatology 2012, 55:336-342.

33. Thompson AJ, Muir AJ, Sulkowski MS, Ge D, Fellay J, Shianna KV, Urban T, Afdhal NH, Jacobson IM, Esteban R, Poordad F, Lawitz EJ, McCone J, Shiffman ML, Galler GW, Lee WM, Reindollar R, King JW, Kwo PY, Ghalib RH, Freilich B, Nyberg LM, Zeuzem S, Poynard T, Vock DM, Pieper KS, Patel K, Tillmann HL, Noviello S, Koury K, Pedicone LD, Brass CA, Albrecht JK, Goldstein DB, McHutchison JG: Interleukin-28B polymorphism improves viral kinetics and is the strongest pretreatment predictor of sustained virologic response in genotype 1 hepatitis C virus. Gastroenterology 2010, 139:120-129.

34. Mangia A, Thompson AJ, Santoro R, Piazzolla V, Copetti M, Minerva N, Petruzzellis D, Mottola L, Bacca D, McHutchison JG: Limited use of interleukin 28B in the setting of response-guided treatment with detailed on-treatment virological monitoring. Hepatology 2011, 54:772-780.

35. Nattermann J, Timm J, Nischalke HD, Olbrich A, Michalk M, Tillmann HL, Berg T, Wedemeyer H, Tenckhoff H, Wiese M, Kullig U, Göbel U, Capka E, Schiefke I, Güthof W, Grüngreiff K, König I, Roggendorf M, Sauerbruch T, Spengler U; East German HCV Study Group: The predictive value of IL28B gene polymorphism for spontaneous clearance in a single source outbreak cohort is limited in patients carrying the CCR5 $\triangle 32$ mutation. J Hepatol 2011, 55:1201-1206.

36. O'Brien TR, Everhart JE, Morgan TR, Lok AS, Chung RT, Shao Y, Shiffman ML, Dotrang M, Sninsky JJ, Bonkovsky HL, Pfeiffer RM; HALT-C Trial Group: An IL28B genotype-based clinical prediction model for treatment of chronic hepatitis C. PLoS One 2011, 6:e20904.

37. Lagging M, Askarieh G, Negro F, Bibert S, Söderholm J, Westin J, Lindh M, Romero A, Missale G, Ferrari C, Neumann AU, Pawlotsky JM, Haagmans BL, Zeuzem S, Bochud PY, Hellstrand K; DITTO-HCV Study Group: Response prediction in chronic hepatitis C by assessment of IP-10 and IL28B-related single nucleotide polymorphisms. PLoS One 2011, 6:e17232

38. Falleti E, Bitetto D, Fabris C, Fattovich G, Cussigh A, Cmet S, Ceriani E, Fornasiere E, Pasino M, leluzzi D, Pirisi M, Toniutto P: Vitamin D binding protein gene polymorphisms and baseline vitamin $D$ levels as predictors of antiviral response in chronic hepatitis C. Hepatology 2012, 56:1641-1650.

39. Clausen LN, Astvad K, Ladelund S, Larsen MV, Schønning K, Benfield T: Hepatitis C viral load, genotype 3 and interleukin-28B CC genotype predict mortality in HIV and hepatitis C-coinfected individuals. AIDS 2012, 26:1509-1516.

40. Parczewski M, Bander D, Leszczyszyn-Pynka M, Urbańska A, Socha L, BorońKaczmarska A: IL28B CC genotype is associated with higher all-cause mortality in antiretroviral-treated HIV-infected patients. AIDS Res Hum Retroviruses 2012, 28:1640-1646.

41. Vispo E, Rallon NI, Labarga P, Barreiro P, Benito JM, Soriano V: Different impact of IL28B polymorphisms on response to peginterferon-á plus ribavirin in HIV-positive patients infected with HCV subtypes 1a or 1b. J Clin Virol 2012, 55:58-61.

42. Dayyeh BK, Gupta N, Sherman KE, de Bakker PI, Chung RT: Aids Clinical Trials Group A5178 Study Team. IL28B alleles exert an additive dose effect when applied to HCV-HIV coinfected persons undergoing peginterferon and ribavirin therapy. PLoS One 2011, 6:e25753.

43. Tanaka Y, Kurosaki M, Nishida N, Sugiyama M, Matsuura K, Sakamoto N, Enomoto N, Yatsuhashi H, Nishiguchi S, Hino K, Hige S, Itoh Y, Tanaka E, Mochida S, Honda M, Hiasa Y, Koike A, Sugauchi F, Kaneko S, Izumi N, Tokunaga K, Mizokami M: Genome-wide association study identified ITPA/ DDRGK1 variants reflecting thrombocytopenia in pegylated interferon and ribavirin therapy for chronic hepatitis C. Hum Mol Genet 2011, 20:3507-3516.

44. Thompson AJ, Clark PJ, Singh A, Ge D, Fellay J, Zhu M, Zhu Q, Urban TJ, Patel K, Tillmann HL, Naggie S, Afdhal NH, Jacobson IM, Esteban R, Poordad F, Lawitz EJ, McCone J, Shiffman ML, Galler GW, King JW, Kwo PY, Shianna KV, Noviello S, Pedicone LD, Brass CA, Albrecht JK, Sulkowski MS, Goldstein DB, McHutchison JG, Muir AJ: Genome-wide association study of 
interferon-related cytopenia in chronic hepatitis C patients. J Hepatol 2012, 56:313-319.

45. Martin MP, Qi Y, Goedert JJ, Hussain SK, Kirk GD, Hoots WK, Buchbinder S, Carrington M, Thio CL: IL28B polymorphism does not determine outcomes of hepatitis B virus or HIV infection. J Infect Dis 2010, 202:1749-1753.

46. Peng $\amalg$, Guo JS, Zhang Z, Shi H, Wang J, Wang JY: IL28B rs12979860 polymorphism does not influence outcomes of hepatitis $B$ virus infection. Tissue Antigens 2012, 79:302-305.

47. Sonneveld MJ, Wong VW, Woltman AM, Wong GL, Cakaloglu Y, Zeuzem S, Buster EH, Uitterlinden AG, Hansen BE, Chan HL, Janssen HL: Polymorphisms near IL28B and serologic response to peginterferon in HBeAg-positive patients with chronic hepatitis B. Gastroenterology 2012, 142:513-520.

48. Wu X, Xin Z, Zhu X, Pan L, Li Z, Li H, Liu Y: Evaluation of susceptibility locus for response to interferon-á based therapy in chronic hepatitis B patients in Chinese. Antiviral Res 2012, 93:297-300.

49. Poordad F, Bronowicki J, Gordon SC, Zeuzem S, Jacobson IM, Sulkowski MS, Poynard T, Morgan TR, Burroughs M, Sniukiene V, Boparai N, Brass CA,
Albrecht JK, Bacon BR: IL28B polymorphism predicts virologic response in patients with hepatitis $C$ genotype 1 treated with Boceprevir combination. Hepatology 2011, 54(Suppl 1):S6.

50. Jacobson IM, Catlett I, Marcellin P, Bzowej NH, Muir AJ, Adda N, Bengtsson L, George S, Seepersaud S, Ramachandran R, Sussky K, Kauffman RS, Botfield M: Telaprevir substantially improved SVR rates across all IL28B genotypes in the ADVANCE trial. J Hepatol 2011, 54(Suppl 1): S542-S543.

51. Thompson AJ, MCHutchison JG: Will IL28B polymorphism remain relevant in the era of direct-acting antiviral agents for hepatitis C virus? Hepatology 2012, 56:373-381.

doi:10.1186/gm400

Cite this article as: Booth DR, et al:: Pharmacogenomics of hepatitis $C$

infections: personalizing therapy. Genome Medicine 2012, 4:99. 